\title{
In Silico Analysis of Sea Urchin Pigments as Potential Therapeutic Agents Against SARS-CoV-2: Main Protease (Mpro) as a Target.
}

Tamara Rubilar, Elena Susana Barbieri, Ayelén Gázquez, Marisa Avaro, Mercedes Vera-Piombo, Agustín Gittardi, Erina Noé Seiler, Jimena Pía Fernandez, Lucas Sepulveda, Florencia Chaar

Submitted date: 02/07/2020 - Posted date: 03/07/2020

Licence: CC BY-NC-ND 4.0

Citation information: Rubilar, Tamara; Barbieri, Elena Susana; Gázquez, Ayelén; Avaro, Marisa; Vera-Piombo, Mercedes; Gittardi, Agustín; et al. (2020): In Silico Analysis of Sea Urchin Pigments as Potential Therapeutic Agents Against SARS-CoV-2: Main Protease (Mpro) as a Target.. ChemRxiv. Preprint. https://doi.org/10.26434/chemrxiv.12598487.v1

The SARS-CoV-2 outbreak has spread rapidly and globally generating a new coronavirus disease (COVID-19) since December 2019 that turned into a pandemic. Effective drugs are urgently needed and drug repurposing strategies offer a promising alternative to dramatically shorten the process of traditional de novo development. Based on their antiviral uses, the potential affinity of sea urchin pigments to bind main protease (Mpro) of SARS-CoV-2 was evaluated in silico. Docking analysis was used to test the potential of these sea urchin pigments as therapeutic and antiviral agents. All pigment compounds presented high molecular affinity to Mpro protein. However, the 1,4-naphtoquinones polihydroxilate (Spinochrome A and Echinochrome A) showed high affinity to bind around the Mpro's pocket target by interfering with proper folding of the protein mainly through an H-bond with Glu166 residue. This interaction represents a potential blockage of this protease's activity. All these results provide novel information regarding the uses of sea urchin pigments as antiviral drugs and suggest the need for further in vitro and in vivo analysis to expand all therapeutic uses against SARS-CoV-2.

File list (3)

Rubilar et al_Mpro_ChemR.pdf (416.18 KiB) view on ChemRxiv • download file Figure 2.pdf $(97.31 \mathrm{KiB})$ view on ChemRxiv - download file 


\title{
In silico analysis of sea urchin pigments as potential therapeutic agents against SARS-CoV-2: Main protease (Mpro) as a target
}

\author{
$\underline{\text { Rubilar Tamara }}^{1,3}$ a $^{*} ;$ Elena S. Barbieri ${ }^{2,3 *}$; Gázquez Ayelén ${ }^{4}$; Avaro Marisa ; Vera-Piombo \\ Mercedes ${ }^{1,3}$; Gittardi Agustín ${ }^{1}$; Seiler, Erina Noé2,3 ; Fernández, Jimena Pia ${ }^{1,3}$; Sepúlveda, \\ Lucas $^{1,3}$ and Chaar, Florencial. \\ *Both authors contributed equally to the manuscript \\ 1. Laboratorio de Química de Organismos Marinos - Instituto Patagónico del Mar- \\ UNPSJB, Puerto Madryn, Chubut, Argentina \\ 2. Laboratorio de Virología - Instituto Patagónico del Mar-UNPSJB, Puerto Madryn, \\ Chubut, Argentina \\ 3. Laboratorio de Oceanografia Biológica - CESIMAR -CONICET, Puerto Madryn, \\ Chubut, Argentina \\ 4. Instituto Tecnológico de Chascomús, InTeCh-CONICET, Chascomús, Buenos Aires, \\ Argentina \\ a*Corresponding author: rubilar@cenpat-conicet.gob.ar \\ Postal address: Boulevard Brown 2915, Puerto Madryn (9120), Chubut, Argentina.
}

\begin{abstract}
.
The SARS-CoV-2 outbreak has spread rapidly and globally generating a new coronavirus disease (COVID-19) since December 2019 that turned into a pandemic. Effective drugs are urgently needed and drug repurposing strategies offer a promising alternative to dramatically shorten the process of traditional de novo_development. Based on their antiviral uses, the potential affinity of sea urchin pigments to bind main protease (Mpro) of SARS-COV-2 was evaluated in silico. Docking analysis was used to test the potential of these sea urchin pigments as therapeutic and antiviral agents. All pigment compounds presented high molecular affinity to Mpro protein. However, the 1,4-naphtoquinones polihydroxilate (Spinochrome A and Echinochrome A) showed high affinity to bind around the Mpro's pocket target by interfering with proper folding of the protein mainly through an H-bond with Glu166 residue. This interaction represents a potential blockage of this protease's activity. All these results provide novel information regarding the uses of sea urchin pigments as antiviral drugs and suggest the need for further in vitro and in vivo analysis to expand all therapeutic uses against SARS-CoV2.
\end{abstract}

Keywords: 2019 pandemic; 1,4-naphtoquinones polihydroxilate; Spinochrome A; Echinochrome A; antiviral drug. 
The novel SARS-CoV-2 is an enveloped, positive-sense, single-stranded RNA virus belonging to the order Nidovirales, family Coronaviridae, subfamily Coronavirinae which has generated a new coronavirus disease (COVID-19) worldwide. Coronaviruses (CoVs) have the ability to infect multiple species with rapid change through recombination; this constitutes an ongoing threat to human health. Three betacoronaviruses have crossed the species barrier and produced deadly pneumonia in humans: severe acute respiratory syndrome coronavirus (SARS-CoV), Middle-East respiratory syndrome coronavirus (MERS-CoV), and SARS-CoV-2 causal agent of the COVID-19 pandemic. Coronaviruses code dozens of proteins, some of them involved in viral replication and entry into cells. As the most abundant protein in the betacoronaviruses virion structure, the main protease (Mpro, monomer between 25-30 kDa) is responsible for the structure and it is inserted into the envelope through three transmembrane domains. The amino constitutes a small ectodomain and can be modified by glycosylation which influences the tropism of the organs to be infected, such as the interferon-inducing capacity (IFN) of some coronaviruses. Therefore, the Mpro is considered the engine for the assembly of viral particles (Perrier et al., 2019), and it constitutes a suitable drug target since it is a key enzyme for coronavirus replication (Zhang et al., 2020a). The Mpro sequence is highly conserved within Coronaviruses. The viral replication can be inhibited in the active site in Mpro of SARS-CoV (Jin et al., 2020), which is located in the same position in SARS-CoV and SARS-CoV-2 between domain I (8-99 aa) and domain II (100-183 aa). Mpro presents flexibility in the binding site conformation constituting a good target for small drugs (Bzowka et al., 2020; Bzówka et al., 2020).

With the lack of available therapies and vaccines for COVID-19 treatment, scientists around the world have expanded and ramped up research on identifying promising inhibitors for preventive and supportive therapies. Drug repositioning is a recommended approach to face an unmet medical need for a new disease like COVID-19 (Pushpakom et al., 2018; Rosa and Santos, 2020). The molecular docking approach may predict the binding site on a complimentary basis in terms of the ligand and the target (Kitchen et al., 2004). Recent results of in silico docking analysis have indicated that certain positive bioactive compounds could be potent inhibitors of Mpro (Khaerunnisa et al., 2020; Pendyalaa and Patrasa, 2020).

Natural bioactive compounds are being extracted from a wide variety of sources, offering fewer side effects and accessible costs. Although research on marine natural products dates back more 
74 than 50 years, only a few compounds have resulted in clinical trials and even fewer have been 75 approved (Serive and Bach, 2018). A large number of pigments have photoprotection, anti76 inflammatory and antioxidant effects, among other properties (Serive and Bach, 2018), leading 77 to their use in cosmetics, functional food, nutraceutical and pharmaceutical products. Natural pigments incur no toxicity and that is why humans have been using them for clinical purposes. The relationship between food and health is known and well documented (Moniruddin, 2020; Syed, 2020).

Sea urchins are marine echinoderms that have been consumed by humans since ancient times (Rubilar and Crespi-Abril, 2017). In Asian culture, the sea urchin appears as far as long ago as in the "Materia Medica" of the Ming Dynasty author by Li Zhongli in 1647. In Chinese medicine, sea urchin roe is known for its benefits to the heart, bones, blood and also it counteracts impotence. Sea urchins can have different types of pigments such as carotenoids (astanxanthin, fucoxanthin and $\beta$-carotene) and 1,4-naphtoquinones polihydroxilate (commonly known as Spinochromes) (Cirino et al., 2017; Vasileva et al., 2017). Currently, there are now numerous studies that demonstrate the use of pigments to prevent cardiovascular and neurodegenerative diseases, as well as their antidiabetic, antiparasitic, anti-inflammatory, anti-obesity, anti-age-related macular degeneration, anticancer, and immunostimulatory effects (Serive and Bach, 2018). Nowadays the most common use of natural pigments is related to the nutraceutical and cosmeceutical industries. To reach the pharmaceutical market, bioactive pigments must satisfy pharmacokinetic descriptions, clinical studies, and regulation requirements.

In order to contribute to the identification of new drugs targeting the SARS-CoV-2 main protease and because sea urchin pigments are promising molecules, the aim of this in silico study was to evaluate the potential binding affinity of sea urchin pigments on Mpro through a docking analysis.

\section{Methodology}

\section{$\underline{\text { Protein and ligands preparation }}$}

The receptor preparation was done according to Forli et al. (Forli et al., 2016) with modifications. The molecular 3D structure of SARS-CoV-2 Mpro protein co-crystalized with an inhibitor was obtained from Protein Data Base PDB (https://www.rcsb.org/): 6LU7, 
resolution $2.16 \AA$ (Kris-Etherton et al., 2002; Xu et al., 2020; Zhang et al., 2020b). Water and

106 ligand molecules were removed from the file and the software AutoDockTools (ADT version

107 1.5.7) was used for receptor and ligands preparation. Polar hydrogens were added and the partial

108 Kollman charges were assigned to the proteins.

109 The co-crystallized N3 ligand was extracted from the PDB structure and polar hydrogens and

110 Gasteiger charges were added through the ADT software. The prepared structure was saved in 111 .pdbqt format.

112 The SMILE of sea urchin pigments Spinochomre A, Echinochrome A, $\beta$-carotene, astaxanthin 113 and fucoxanthin and drugs Carmofur, Cinanserin, Disulfiram, Ebselen, PX-12, Shikonin,

114 TDZD-8 and Tideglusib were downloaded from Chemical Entities of Biological Interest 115 (ChEBI) and PubChem (https://pubchem.ncbi.nlm.nih.gov/), transformed to PDB and polar 116 hydrogens and Gasteiger charges were added and saved in .pdbqt format by ADT software. In 117 the case of Ebselen the selenium atom was changed for a sulfur because otherwise it was not 118 possible to perform the molecular docking analysis.

Molecular docking

121 The docking simulations were performed using AutoDock vina 1.1.2 (Trott and Olson, 2010).

122 The center of the search space for Mpro dockings (-9.732, 11.403, 68.483) have been 123 determined on the basis of the co-crystallized bound N3 ligand, and its size has been set to $12420 \times 20 \times 20 \AA$ to cover the active site of the protease. The exhaustiveness has been set to 24 in 125 all docking analyses while the remaining AutoDock Vina parameters have been kept at default 126 values. The results of the docking experiments have been ranked according to their Vina score 127 and docking poses were visually inspected with UCSF Chimera software (Pettersen et al., 128 2004).

129 In the case of Echinochrome A, the top ranked candidates were selected for further analysis of 130 protein-ligand interactions. Hydrogen bonds (H-bonds) were detected with UCSF Chimera 131 relax H-bonds constraints $\left(0.5 \AA\right.$ and $\left.25^{\circ}\right)$. All direct interactions were also identified as clashes 132 and contact. Note that clashes are unfavorable interactions where atoms are too close together, 133 with contacts denoting all kinds of direct interactions (polar and nonpolar, favorable and 134 unfavorable), including clashes. 
136 As a validation protocol for Mpro analysis, the co-crystallized N3 peptide was removed and 137 redocked with the substrate-binding site of SARS-CoV-2 Mpro (6LU7) by using the same 138 docking parameters. The generated re-docked pose was quite similar to the co-crystalized conformation (RMSD $5.496 \AA$ ).

140

Results and Discussion

142

143 This study was focused on the potential of sea urchin pigments as antiviral drugs by inhibiting

144 Mpro activity since they are small molecules (Table 1). These pigments share the common 145 property of being antioxidant molecules. Carotenoids have different common biological 146 functions due to their chemical structure. They are characterized by the covalent chemical 147 bonding of polyene units, constituting a skeleton of at least 40 carbon atoms with conjugated 148 double bonds which provide an extensive cloud of pi electrons that interact with free radicals 149 conferring their antioxidant capacity (Galasso et al., 2017; Young and Lowe, 2018). This family 150 of pigments includes carotenes and xanthophylls. Carotenes, such as $\beta$-carotene, have only 151 carbon and hydrogen atoms and are therefore hydrophobic while xanthophylls, such as 152 astaxanthin and fucoxanthin, have oxygen in their terminal rings, making them somewhat more 153 polar than carotenes and enhancing their antioxidant properties (Galasso et al., 2017). The 1,4154 naphtoquinones polyhydroxylated, such as Spinochrome A (SpinA) and Echinochrome A 155 (EchA) have a chemical structure that include several hydroxylated groups which are 156 appropriate for free-radical scavenging, diminishing ROS and preventing redox imbalance 157 (Jeong et al., 2014). The position of $\mathrm{OH}$ groups and number in the quinoid fragment may be 158 important since the $\mathrm{OH}$ groups in polyhydroxylated 1,4-naphthoquinones in the R1, R2, and R5 159 positions play key roles in both iron-ion complexing and free radical scavenging (Lebedev et 160 al., 2008).

161

162

163

164 
166 Table 1. Potentially bioactive pigments in sea urchins.

\begin{tabular}{|c|c|c|c|c|}
\hline $\begin{array}{c}\mathbf{N} \\
\circ\end{array}$ & $\begin{array}{c}\text { Compound } \\
\text { Name }\end{array}$ & $\begin{array}{c}\text { IUPAC Compound } \\
\text { Name }\end{array}$ & 2D Lineal Structure & $\begin{array}{c}\text { Molecula } \\
\text { r } \\
\text { Weight } \\
\left(\mathrm{g} \mathrm{mol}^{-1}\right) \\
\end{array}$ \\
\hline 1 & $\begin{array}{c}\text { Spinochrome } \\
\text { A }\end{array}$ & $\begin{array}{l}\text { 1,4-Naphthalenedione, 2-acetyl- } \\
\text { 3,5,6,8-tetrahydroxy } \\
\text { 6-acetyl-4,5,7,8- } \\
\text { tetrahydroxynaphthalene-1,2-dione } \\
\text { 2-Acetyl-3,6-dihydroxynaphthazarin } \\
\text { Spinochrome A } \\
\text { 1. o (Yabuzaki.J } \\
\text { 2015) }\end{array}$ & (2) $\mathrm{o}$ (CChemExper Inc) & 264.19 \\
\hline 2 & $\begin{array}{c}\text { Echinochrom } \\
\text { e A }\end{array}$ & $\begin{array}{l}\text { 6-ethyl-2,3,5,7,8-pentahydroxy-1,4- } \\
\text { Naphthoquinone, } \\
\text { 6-ethyl-2,3,5,7,8-pentahydroxy-1,4- } \\
\text { Naphthalenedione, } \\
\text { 6-Ethyl-2,3,7- } \\
\text { trihydroxynaphthazarin } \\
\text { (4) o ( OChemExper Inc) }\end{array}$ & (3) $\mathrm{o}($ PubChem $\mathbb{R})$ & 266.22 \\
\hline 3 & $\beta$-Carothene & $\begin{array}{c}\text { 1,3,3-Trimethyl-2- } \\
\text { [(1E,3E,5E,7E,9E,11E,13E, } 15 \mathrm{E}, 17 \mathrm{E} \\
\text { )-3,7,12,16-tetramethyl-18-(2,6,6- } \\
\text { trimethylcyclohexen-1-yl)octadeca- } \\
\text { 1,3,5,7,9,11,13,15,17- } \\
\text { nonaenyl]cyclohexene } \\
\\
{ }^{(5)} \underline{\text { S. Kim et al., } 2016}\end{array}$ & (6) ohttps://hmdb.ca & 536.87 \\
\hline 4 & Astaxanthine & $\begin{array}{c}\text { (6S)-6-hydroxy-3- } \\
\text { [(1E,3E,5E,7E,9E,11E,13E,15E,17E } \\
\text { )-18-[(4S)-4-hydroxy-2,6,6- } \\
\text { trimethyl-3-oxocyclohexen-1-yl]- } \\
\text { 3,7,12,16-tetramethyloctadeca- } \\
\text { 1,3,5,7,9,11,13,15,17-nonaenyl]- } \\
\text { 2,4,4-trimethylcyclohex-2-en-1-one } \\
\text { (7) o (S. Kim et al., 2016) }\end{array}$ & (7) o ( PubChem ${ }^{\circledR)}$ & 596.80 \\
\hline 5 & Fucoxanthin & $\begin{array}{c}\text { [(1S,3R)-3-hydroxy-4- } \\
\text { [(3E,5E,7E,9E,11E,13E,15E)-18- } \\
\text { [(1S,4S,6R)-4-hydroxy-2,2,6- } \\
\text { trimethyl-7- } \\
\text { oxabicyclo[4.1.0]heptan-1-yl]- } \\
\text { 3,7,12,16-tetramethyl-17- } \\
\text { oxooctadeca-1,3,5,7,9,11,13,15- } \\
\text { octaenylidene]-3,5,5- } \\
\text { trimethylcyclohexyl] acetate } \\
\text { (9) o (PubChem } \mathbb{R})\end{array}$ & 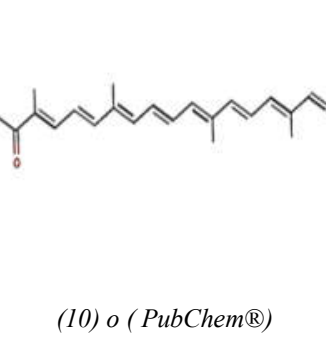 & 658.90 \\
\hline
\end{tabular}


168 The ability of these molecules to interact with SARS-CoV-2 main protease (Mpro) was analyzed. Recently, Jin et al (Jin et al., 2020) identified new drugs that are able to inhibit this enzyme and hence they were included for comparison. The binding energies obtained from molecular docking analysis of Mpro with sea urchin pigments and known drugs are shown in Figure 1. All pigments presented low binding energy which indicates a higher affinity for the viral protein than the rest of the tested compounds (Vina docking scores, from -7.5 to -6.0 Kcal.mol ${ }^{-1}$ ) with the exception of Astaxanthin (Vina docking score -3.0 Kcal.mol ${ }^{-1}$ ). Only Tideglusib showed a higher binding energy than the other tested pigments (Vina docking scores, $\left.-7.9 \mathrm{Kcal}_{\mathrm{mol}}{ }^{-1}\right)$. However, Tideglusib is a drug used in Alzheimer's disease and its ingestion can cause mild-moderate adverse reactions, as transient increases in serum creatine kinase, ALT — or gGT — diarrhea, nausea, cough, fatigue, and headache (Del Ser et al., 2013).

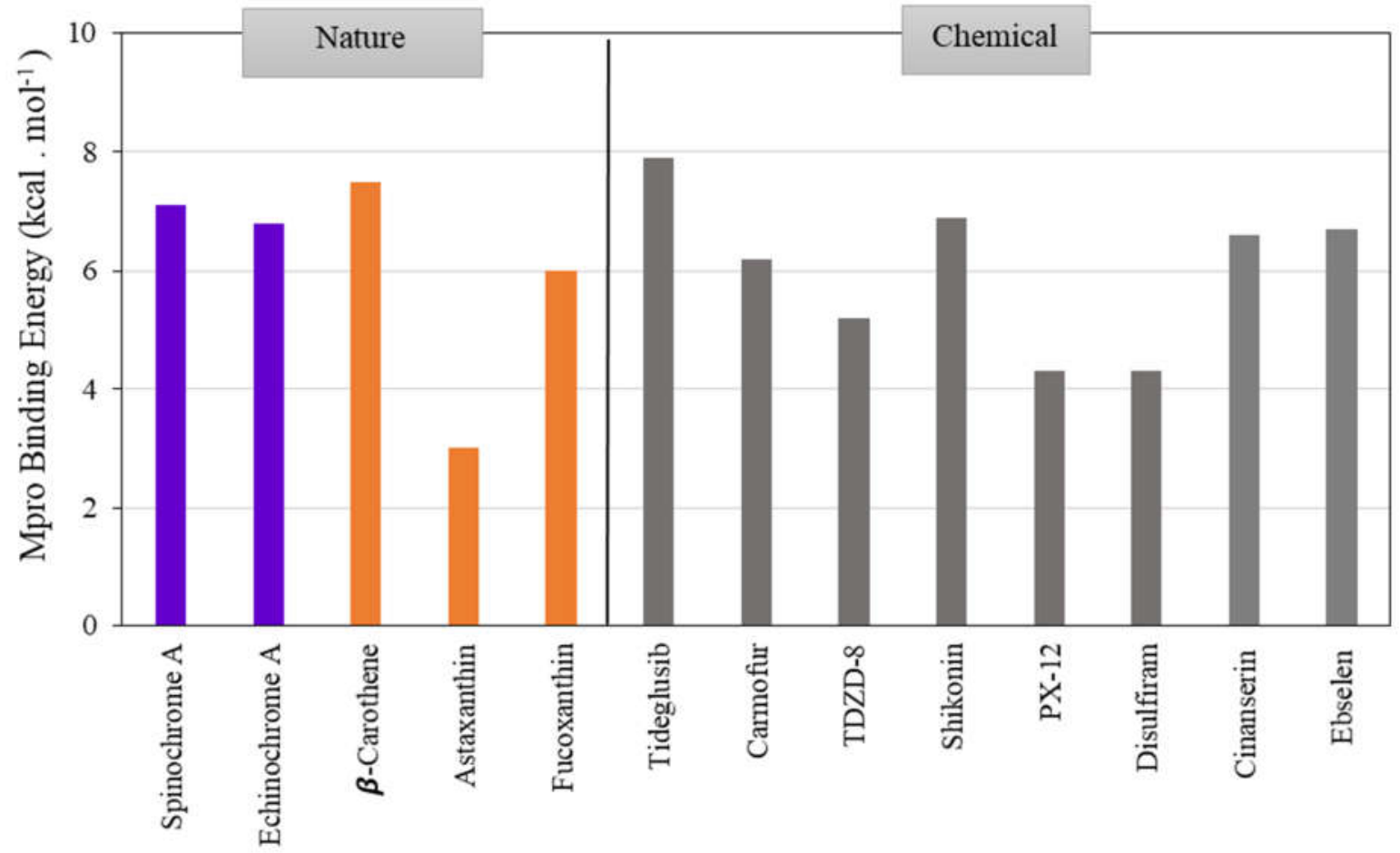

Figure 1. Mpro Binding energies of sea urchin pigments (1,4-naphtoquinones polyhydroxylated in purple; carotenoids in orange) and chemical compounds (in grey) and tested drugs. 
185 Because of Mpro binding site flexibility (Bzowka et al., 2020; Bzówka et al., 2020) and 186 considering that SpinA and EchA are small molecules with high affinity for this protein, the 187 molecular interaction in the binding site was further evaluated. Both spinochromes have high 188 affinity for the viral proteins (Vina docking scores, SpinA: -7.1 Kcal.mol-1 , EchA: -6.8 $189 \mathrm{Kcal}_{\mathrm{mol}}{ }^{-1}$ ), which suggests they are potential antiviral drugs. The best docking pose of SpinA 190 involved seven H-bonds with amino acids S144, C145, H163, E166 and L141, no clashes and 19142 Van der Waals (VdW) contacts with G143, S144, L141, E166, M49, H163, C145, M165, 192 Q189 and H41 (Figure 2). The best docking pose of EchA involved four H-bonds with amino 193 acids S144 and E166, 51 VdW contacts with S144, C145, M165, Q189, E166, L141, M49, 194 G143, H163, F40, H41, and N142 and no clashes (Figure 3). Mpro presents a homodimer with 195 the pocket of the substrate-binding site formed by the interaction of Glu166 from one monomer 196 with Ser1 from the other through an H-bond (Jin et al., 2020; Zhang et al., 2020b). Since EchA 197 is a highly polar molecule, due to the presence of numerous hydroxyl groups, the bond between 198 the Glu166 and EchA may interfere with the dimer interface. This is extremely important 199 because the Mpro dimerization is essential for catalysis (Cheng et al., 2010), and if EchA is 200 able to interfere in this matter it may inactivate Mpro.

201 Spinochromes have been found to have cardioprotective activity against the cytotoxicity of 202 doxorubic (Yoon et al., 2019) and antiallergic effects (Pozharitskaya et al., 2013). However, 203 there is no pharmaceutical products based on SpinA available in the market yet. On the other 204 hand, Echinochrome A (EchA), has satisfied all pharmaceutical requirements and products 205 made from this pigment, have been approved. EchA is the active compound of Histochrome ${ }^{\mathrm{TM}}$ 206 and Gistochrome ${ }^{\mathrm{TM}}$, two Russian preparations for cardiopathies and glaucoma diseases. There

208 Oh et al., 2019; Vasileva et al., 2017). The pharmacological activity observed in patients with 209 various health issues, together with the identified low toxicity profiles, strongly support the 210 potential and therapeutic benefits of these natural pigments for the treatment of various human 211 diseases, particularly inflammation, cardioprotection and diabetes (Shikov et al., 2018).

212 Moreover, in animal models EchA has shown a wide range of biological properties, expanding 213 possible therapeutic applications. For example, treatment with EchA in a neonatal murine 214 model was able to prevent pulmonary fibrosis by reducing bleomycin-induced oxidative stress 215 (Lebed'ko et al., 2015). In another study, mice with inflammatory bowel disease that were 216 treated with EchA showed a reduced mortality and modulated the immune response, reducing 217 inflammation and allowing tissue repair (Oh et al., 2019). In regard to COVID-19, the most 
important application is the in vitro antiviral evidences of EchA against certain types of human

219 viruses, such as tick-borne encephalitis virus (TBEV) and herpes simplex virus type 1 (HSV-

220 1) (Fedoreyev et al., 2018). In these studies, infected cells were treated with EchA in combination with the antioxidants ascorbic acid and $\alpha$-tocopherol in a ratio of 5:5:1, proving to

222

223

224

225 be a mixture with powerful antiviral effects (Fedoreyev et al., 2018). The combination of EchA and the other antioxidants was able to neutralize virus infection, probably preventing the adsorption of the virus to the host cell receptors or causing damage in the viral capsid protein as it has been reported in other cases (Astani and Schnitzler, 2014; Fedoreyev et al., 2018; Garrett et al., 2012; Torky and Hossain, 2017). The antiviral activity of EchA with ascorbic acid and $\alpha$-tocopherol has been hypothesized also to be a result of the interference with the redox imbalance normally caused by these viruses, resulting in no cytotoxicity (Di Sotto et al., 2018). EchA has the ability to improve oxygen supply to peripheral tissues and due to its antioxidant power it protects the mitochondria, improving the rate of oxygen consumption, the production of ATP and the regulation of the transcription of some genes (Vasileva et al., 2017). As a consequence, EchA acts directly, either alone or in combination, on virus particles by inactivating them, and also acts indirectly improving antioxidant defense mechanisms of the host cell.

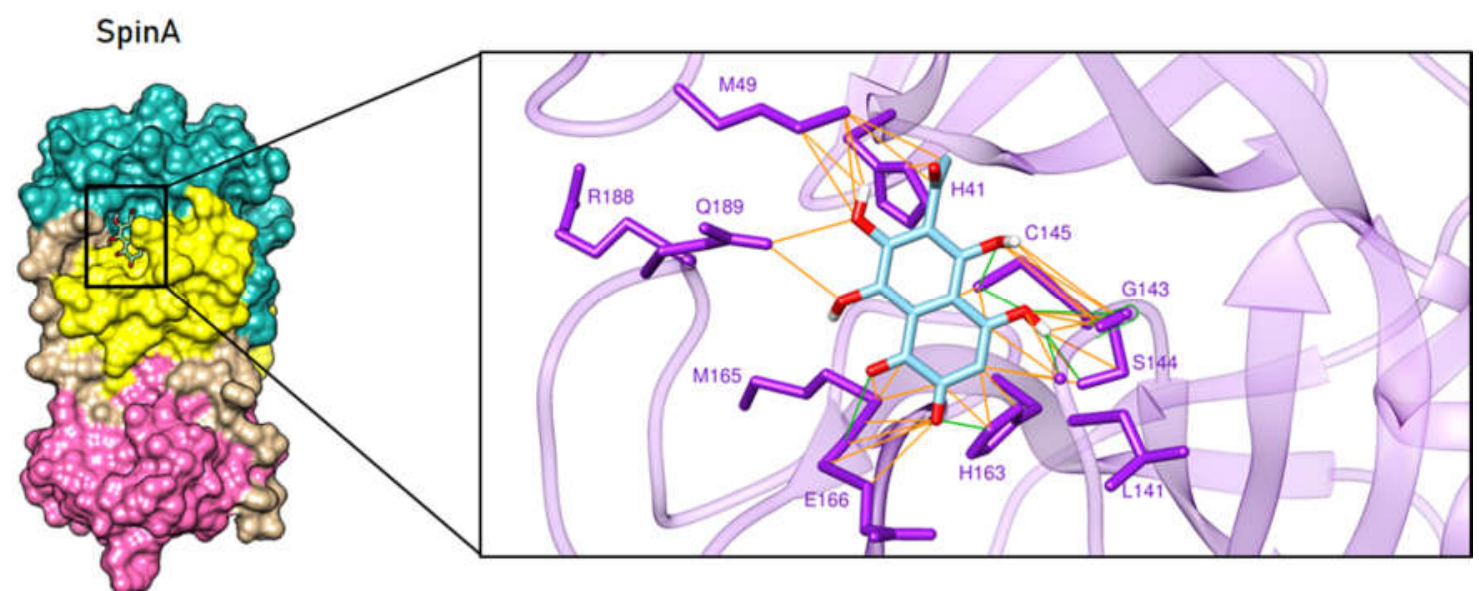

Figure 2. One protomer of SARS-CoV-2 Mpro interaction with SpinA presents the best docking pose. On the left, SpinA is shown binded with the Mpro binding pocket. Mpro domains are shown in different colours, Domain I (residues 8-101) in aquamarine, Domain II (residues 102-184) in yellow and Domain III (residues 201-303) in pink. On the left, there is a zoomed view of the substrate-binding pocket with the best docking pose of SpinA. The key residues forming the binding pocket are shown in sticks and labeled. 
245

246

247

248

249

250

251

252

253

254

255

256

257

258

259

260

261

\section{Conclusion}

263

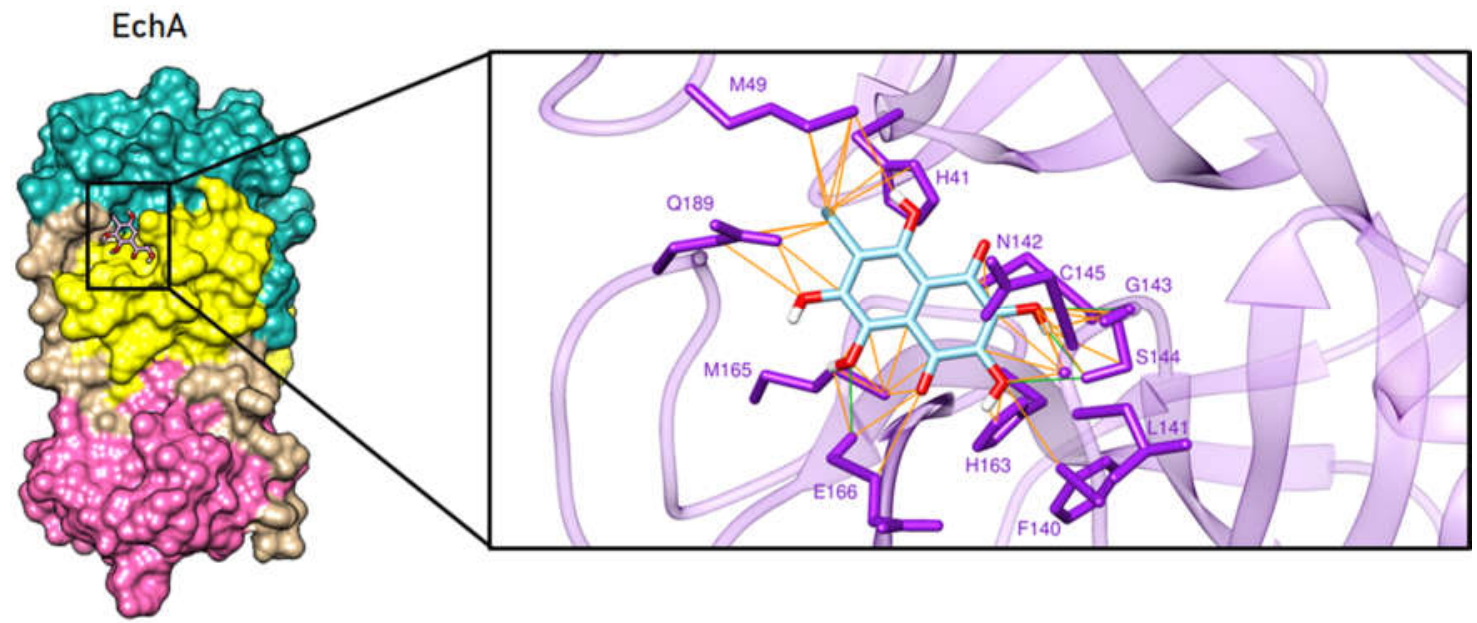

Figure 3. One protomer of SARS-CoV-2 Mpro interaction with EchA best docking pose. On the left EchA is shown binded with the Mpro binding pocket. Mpro domains are shown in different colours, Domain I (residues 8-101) in aquamarine, Domain II (residues 102184) in yellow and Domain III (residues 201-303) in pink. On the left, there is a zoomed view of the substrate-binding pocket with the best docking pose of EchA. The key residues forming the binding pocket are shown in sticks and labeled.

EchA is already used as a drug therapy in humans and it also showed a good binding affinity to Mpro. The three-dimensional structures of Mpro of SARS-CoV and SARS-CoV-2 are quite similar. Both enzymes have a half-site activity and they only differ in a few amino acids and SARS-CoV-2 Mpro enzyme has a slightly higher catalytic activity (Jin et al., 2020; Zhang et al., 2020b). Moreover, substrate-binding pockets and substrate specificity from different $\mathrm{CoV}$ Mpro enzymes are conserved and suggest that targeting this site may lead to broad-spectrum inhibitors (Hegyi and Ziebuhr, 2002; Jin et al., 2020). Therefore, in vitro testing of Mpro of SARS-CoV and SARS-CoV-2 by EchA is necessary to confirm the inhibitory capacity.

In this in silico study, we used molecular docking to evaluate the potential interaction of natural sea urchin pigments with the Mpro protein of SARS-CoV-2. All pigment compounds presented a high molecular affinity to Mpro protein. However, EchA, a sea urchin pigment belonging to the family 1,4-naphtoquinones polihydroxilate, interacted with very high affinity to Mpro binding site. This may be related to its small size and the $\mathrm{H}$-bond interactions between $\mathrm{OH}$ groups of EchA and Glu166 probably blocking the activity of Mpro. EchA is a natural marine pigment found in the test and spines of most sea urchin species in low concentrations. However, 
it is highly concentrated in the eggs of the sea urchin Arbacia dufresnii in aquaculture systems and hence it is available from a natural marine source. All these results provide novel information regarding sea urchin pigments as antiviral drugs against SARS-CoV-2, suggesting the need for further analysis to expand therapeutic uses.

\section{Acknowledgments}

We would like to thank Federico Lois for his helpful insight in the manuscript, to Dr. Viviana Parreño for helping us improve the manuscript and to Katheleen Anderson for helping with the English translation.

\section{References}

Astani, A., Schnitzler, P., 2014. Antiviral activity of monoterpenes beta-pinene and limonene against herpes simplex virus in vitro. Iran. J. Microbiol.

Bzowka, M., Mitusinska, K., Raczynska, A., Samol, A., Tuszynski, J.A., Gora, A., 2020. Molecular Dynamics Simulations Indicate the COVID-19 Mpro Is Not a Viable Target for Small-Molecule Inhibitors Design. bioRxiv. https://doi.org/10.1101/2020.02.27.968008

Bzówka, M., Mitusińska, K., Raczyńska, A., Samol, A., Tuszyński, J.A., Góra, A., 2020. Structural and evolutionary analysis indicate that the sars-COV-2 mpro is a challenging target for small-molecule inhibitor design. Int. J. Mol. Sci. https://doi.org/10.3390/ijms21093099

Cheng, S.C., Chang, G.G., Chou, C.Y., 2010. Mutation of glu-166 blocks the substrate-induced dimerization of SARS coronavirus main protease. Biophys. J. https://doi.org/10.1016/j.bpj.2009.12.4272

Cirino, P., Brunet, C., Ciaravolo, M., Galasso, C., Musco, L., Fernández, T.V., Sansone, C., Toscano, A., 2017. The sea urchin arbacia lixula: A novel natural source of astaxanthin. Mar. Drugs. https://doi.org/10.3390/md15060187

Del Ser, T., Steinwachs, K.C., Gertz, H.J., Andrés, M. V., Gómez-Carrillo, B., Medina, M., Vericat, J.A., Redondo, P., Fleet, D., León, T., 2013. Treatment of Alzheimer's disease with the GSK-3 inhibitor tideglusib: A pilot study. J. Alzheimer's Dis. https://doi.org/10.3233/JAD-2012-120805

Di Sotto, A., Checconi, P., Celestino, I., Locatelli, M., Carissimi, S., De Angelis, M., Rossi, V., Limongi, D., Toniolo, C., Martinoli, L., Di Giacomo, S., Palamara, A.T., Nencioni, L., 2018. Antiviral and antioxidant activity of a hydroalcoholic extract from humulus lupulus L. Oxid. Med. Cell. Longev. https://doi.org/10.1155/2018/5919237

Fedoreyev, S.A., Krylova, N. V., Mishchenko, N.P., Vasileva, E.A., Pislyagin, E.A., Iunikhina, O. V., Lavrov, V.F., Svitich, O.A., Ebralidze, L.K., Leonova, G.N., 2018. Antiviral and antioxidant properties of echinochrome A. Mar. Drugs 16, 1-10. https://doi.org/10.3390/md16120509

Forli, S., Huey, R., Pique, M.E., Sanner, M.F., Goodsell, D.S., Olson, A.J., 2016. 
Computational protein-ligand docking and virtual drug screening with the AutoDock suite. Nat. Protoc. https://doi.org/10.1038/nprot.2016.051

Galasso, C., Corinaldesi, C., Sansone, C., 2017. Carotenoids from marine organisms: Biological functions and industrial applications. Antioxidants. https://doi.org/10.3390/antiox6040096

Garrett, R., Romanos, M.T. V., Borges, R.M., Santos, M.G., Rocha, L., da Silva, A.J.R., 2012. Antiherpetic activity of a flavonoid fraction from Ocotea notata leaves. Brazilian J. Pharmacogn. https://doi.org/10.1590/S0102-695X2012005000003

Hegyi, A., Ziebuhr, J., 2002. Conservation of substrate specificities among coronavirus main proteases. J. Gen. Virol. https://doi.org/10.1099/0022-1317-83-3-595

Jeong, S.H., Kim, H.K., Song, I.S., Lee, S.J., Ko, K.S., Rhee, B.D., Kim, N., Mishchenko, N.P., Fedoryev, S.A., Stonik, V.A., Han, J., 2014. Echinochrome a protects mitochondrial function in cardiomyocytes against cardiotoxic drugs. Mar. Drugs. https://doi.org/10.3390/md12052922

Jin, Z., Du, X., Xu, Y., Deng, Y., Liu, M., Zhao, Y., Zhang, B., Li, X., Zhang, L., Peng, C., Duan, Y., Yu, J., Wang, L., Yang, K., Liu, F., Jiang, R., Yang, Xinglou, You, T., Liu, Xiaoce, Yang, Xiuna, Bai, F., Liu, H., Liu, Xiang, Guddat, L.W., Xu, W., Xiao, G., Qin, C., Shi, Z., Jiang, H., Rao, Z., Yang, H., 2020. Structure of Mpro from SARS-CoV-2 and discovery of its inhibitors. Nature 582, 289-293. https://doi.org/10.1038/s41586-0202223-y

Khaerunnisa, S., Kurniawan, H., Awaluddin, R., Suhartati, S., 2020. Potential Inhibitor of COVID-19 Main Protease ( $\mathrm{M}$ pro ) from Several Medicinal Plant Compounds by Molecular Docking Study. Preprints 1-14. https://doi.org/10.20944/preprints202003.0226.v1

Kitchen, D.B., Decornez, H., Furr, J.R., Bajorath, J., 2004. Docking and scoring in virtual screening for drug discovery: Methods and applications. Nat. Rev. Drug Discov. https://doi.org/10.1038/nrd1549

Kris-Etherton, P.M., Hecker, K.D., Bonanome, A., Coval, S.M., Binkoski, A.E., Hilpert, K.F., Griel, A.E., Etherton, T.D., 2002. Bioactive compounds in foods: Their role in the prevention of cardiovascular disease and cancer, in: American Journal of Medicine. https://doi.org/10.1016/s0002-9343(01)00995-0

Lebed'ko, O.A., Ryzhavskii, B.Y., Demidova, O. V., 2015. Effect of Antioxidant Echinochrome A on Bleomycin-Induced Pulmonary Fibrosis. Bull. Exp. Biol. Med. https://doi.org/10.1007/s10517-015-2960-3

Lebedev, A. V., Ivanova, M. V., Levitsky, D.O., 2008. Iron chelators and free radical scavengers in naturally occurring polyhydroxylated 1,4-naphthoquinones, in: Hemoglobin. https://doi.org/10.1080/03630260701700017

Moniruddin, A., 2020. DIET AND HEALTH. KYAMC J. 10, 171-172. https://doi.org/10.1136/bmj.1.3665.605-a

Oh, S.J., Seo, Y., Ahn, J.S., Shin, Y.Y., Yang, J.W., Kim, H.K., Han, J., Mishchenko, N.P., Fedoreyev, S.A., Stonik, V.A., Kim, H.S., 2019. Echinochrome a reduces colitis in mice and induces in vitro generation of regulatory immune cells. Mar. Drugs. https://doi.org/10.3390/md17110622

Pendyalaa, B., Patrasa, A., 2020. In silico Screening of Food Bioactive Compounds to Predict Potential Inhibitors of COVID-19 Main protease (M. ChemRxiv. 
Perrier, A., Bonnin, A., Desmarets, L., Danneels, A., Goffard, A., Rouillé, Y., Dubuisson, J., Belouzard, S., 2019. The C-terminal domain of the MERS coronavirusMprotein contains a trans-Golgi network localization signal. J. Biol. Chem. 294, 14406-14421. https://doi.org/10.1074/jbc.RA119.008964

Pettersen, E.F., Goddard, T.D., Huang, C.C., Couch, G.S., Greenblatt, D.M., Meng, E.C., Ferrin, T.E., 2004. UCSF Chimera - A visualization system for exploratory research and analysis. J. Comput. Chem. https://doi.org/10.1002/jcc.20084

Pozharitskaya, O.N., Shikov, A.N., Makarova, M.N., Ivanova, S.A., Kosman, V.M., Makarov, V.G., Bazgier, V., Berka, K., Otyepka, M., Ulrichová, J., 2013. Antiallergic effects of pigments isolated from green sea urchin (Strongylocentrotus droebachiensis) shells. Planta Med. https://doi.org/10.1055/s-0033-1351098

Pushpakom, S., Iorio, F., Eyers, P.A., Escott, K.J., Hopper, S., Wells, A., Doig, A., Guilliams, T., Latimer, J., McNamee, C., Norris, A., Sanseau, P., Cavalla, D., Pirmohamed, M., 2018. Drug repurposing: Progress, challenges and recommendations. Nat. Rev. Drug Discov. https://doi.org/10.1038/nrd.2018.168

Rosa, S.G.V., Santos, W.C., 2020. Clinical trials on drug repositioning for COVID-19 treatment. Rev. Panam. Salud Pública. https://doi.org/10.26633/rpsp.2020.40

Rubilar, T., Crespi-Abril, A., 2017. Does echinoderm research deserve an ethical consideration? Rev. Biol. Trop. https://doi.org/10.15517/rbt.v65i1-1.31662

Serive, B., Bach, S., 2018. Marine Pigment Diversity: Applications and Potential. Blue Biotechnol. 643-681. https://doi.org/10.1002/9783527801718.ch20

Shikov, A.N., Pozharitskaya, O.N., Krishtopina, A.S., Makarov, V.G., 2018. Naphthoquinone pigments from sea urchins: chemistry and pharmacology. Phytochem. Rev. https://doi.org/10.1007/s11101-018-9547-3

Syed, I.U.B., 2020. Diet, physical activity, and emotional health: What works, what doesn't, and why we need integrated solutions for total worker health. BMC Public Health. https://doi.org/10.1186/s12889-020-8288-6

Torky, Z.A., Hossain, M.M., 2017. Pharmacological evaluation of the Hibiscus herbal extract against Herpes Simplex Virus-type 1 as an antiviral drug in vitro. Int. J. Virol. https://doi.org/10.3923/ijv.2017.68.79

Trott, O., Olson, A.J., 2010. AutoDock Vina: Improving the Speed and Accuracy of Docking with a New Scoring Function, Efficient Optimization, and Multithreading. J. Comput. Chem. 31, 455-461. https://doi.org/10.1002/jcc

Vasileva, E.A., Mishchenko, N.P., Fedoreyev, S.A., 2017. Diversity of Polyhydroxynaphthoquinone Pigments in North Pacific Sea Urchins. Chem. Biodivers. https://doi.org/10.1002/cbdv.201700182

Xu, Z., Peng, C., Shi, Y., Zhu, Z., Mu, K., Wang, X., Zhu, W., 2020. Nelfinavir was predicted to be a potential inhibitor of 2019-nCov main protease by an integrative approach combining homology modelling, molecular docking and binding free energy calculation. bioRxiv. https://doi.org/10.1101/2020.01.27.921627

Yoon, C.S., Kim, H.K., Mishchenko, N.P., Vasileva, E.A., Fedoreyev, S.A., Shestak, O.P., Balaneva, N.N., Novikov, V.L., Stonik, V.A., Han, J., 2019. The protective effects of echinochrome A structural analogs against oxidative stress and doxorubicin in AC16 cardiomyocytes. Mol. Cell. Toxicol. https://doi.org/10.1007/s13273-019-0044-6 
398 Young, A.J., Lowe, G.L., 2018. Carotenoids-antioxidant properties. Antioxidants. 399 https://doi.org/10.3390/antiox 7020028

400 Zhang, L., Lin, D., Sun, X., Curth, U., Drosten, C., Sauerhering, L., Becker, S., Rox, K.,

401

402

403

404

405

406

407 Hilgenfeld, R., 2020a. Crystal structure of SARS-CoV-2 main protease provides a basis for design of improved a-ketoamide inhibitors. Science (80-. ). https://doi.org/10.1126/science.abb3405

Zhang, L., Lin, D., Sun, X., Curth, U., Drosten, C., Sauerhering, L., Becker, S., Rox, K., Hilgenfeld, R., 2020b. Crystal structure of SARS-CoV-2 main protease provides a basis for design of improved a-ketoamide inhibitors. Science (80-. ). 368, 409-412. https://doi.org/10.1126/science.abb3405

408 


\section{SpinA}

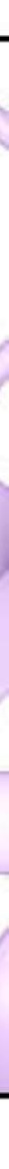




\section{EchA}

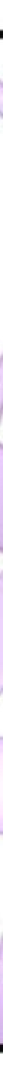


